\title{
NORMAS "CULTAS" E OCULTAS NO ENSINO DA LÍNGUA MATERNA, DA LEITURA E DA PRODUÇÃO TEXTUAL
}

\author{
Isa Ferreira Martins ${ }^{(*)}$ \\ Ao pesquisador cabe compreender, \\ buscar os porquês, as causas, das perguntas que o mundo da educação nos está propondo. \\ E aqui vem o segundo apelo [...], apelo à $A C ̧ \tilde{A} O$. \\ compreender para AGIR. \\ Diante das respostas que o mundo está dando-diante do que é; \\ diante da compreensão, pela pesquisa, do por que é assim, \\ levanta-se o apelo à $A C ̧ \tilde{A} O$. \\ Primeiro, a compreensão, pela pesquisa; \\ Segundo, a ação, que a pesquisa motiva, demanda, mesmo exige \\ $e$, sobretudo, orienta - a ação para transformar. \\ Magda Soares (Destaques da autora)
}

As palavras de Magda Soares que compõem a presente epígrafe são parte do discurso da autora sobre o papel da educação e da pesquisa, ao receber o Prêmio Almirante Álvaro Alberto para a Ciência e Tecnologia, ${ }^{1}$ maior reconhecimento na área do país. Nele, a homenageada nos convida à reflexão ao afirmar que "é Bourdieu quem, definindo com admirável precisão o que deve ser a pesquisa sobre o ser humano e sobre grupos sociais - pesquisar é COMPREENDER -, cita Spinoza para definir o dever de não julgar: Não deplorar, não rir, não detestar, mas compreender." (2015, p. 04, destaque da autora).

Segundo Soares, não cabe ao pesquisador da área de educação "deplorar, por exemplo, o reiterado fracasso em alfabetização, os baixos resultados em leitura e escrita dos alunos, a evasão no ensino médio, os currículos inadequados - estas são respostas que o mundo nos está dando, não cabe deplorá-las, mas compreendê-las (grifos da autora).

E segue nos alertando de que também "não cabe rir dos erros, dos fracassos, das fraquezas não cabe, por exemplo, rir de disparates que aparecem em provas do Enem e circulam pela internet como piadas - são respostas que o mundo nos está dando, não cabe rir delas, mas compreendê-las; (SOARES, 2015, grifos da autora). E chama atenção ainda para o fato de que "não cabe detestar,

\footnotetext{
${ }^{(*)}$ Universidade Federal do Rio de Janeiro (UFRJ). Professora substituta de Didática e Prática de ensino: Português/Literaturas. E-mail: isa2016martins@gmail.com.

${ }^{1}$ [...] O Conselho Nacional de Desenvolvimento Científico e Tecnológico (CNPq/MCTI) entregou [...] a mais importante honraria nacional do setor de ciência e tecnologia à professora e pesquisadora de educação Magda Becker Soares, [...] doutora em didática pela Universidade Federal de Minas Gerais (UFMG). O Prêmio Almirante Álvaro Alberto para a Ciência e Tecnologia é concedido anualmente a um pesquisador que tenha se destacado pela realização de obra científica ou tecnológica de grande valor para o progresso da sua área do conhecimento. [...]. Discurso: Disponível em: http://www.mcti.gov.br/visualizar/-/asset publisher/jIPU0I5RgRmq/content/leia-o-discurso-de-magdasoares-ao-receber-o-premio-almirante-alvaro-alberto;jsessionid=8684DEE68420446E08535A832BB29A0D. Acesso em: 25 jul. 2015.
} 
por exemplo, as mais de 500.000 notas zero nas redações do Enem, como ocorreu em 2014, não cabe detestar a inadequada formação ou atuação dos professores - são respostas que o mundo nos está dando, não cabe detestá-las, mas compreendê-las. (p. 04, grifos da autora).

Nesse sentido, é preciso pesquisar para compreender, para agir. Entretanto, essa ideia não está centrada no entendimento de que a escola seja o grande caminho para a transformação social, pelas inúmeras questões que a limitam. Assim, é necessário deslocar para o extra-escolar a responsabilidade coletiva pela ação para a transformação. Porém, não se pode tirar da escola sua contribuição na manutenção ou na mudança de dado contexto social.

Parece haver ampla concordância no reconhecimento de que a escola deve munir nossos estudantes de conhecimentos sobre o trabalho com a linguagem para que deem conta dos desafios e práticas sociais futuras. Porém, é isso que efetivamente se faz nas escolas? E quando é feito, estão os estudantes munidos de saberes sobre a produção ou essencialmente reprodução de modelos e ideias? Formulação ou formatação?

A "formulação" é entendida "como possibilidade de articular, expressar, produzir novas sínteses provisórias" (BARRETO, 1994, p. 136). Já "a formatação como impedimento, apagando os processos anteriores pela imposição de um formato que, como tal, está necessariamente pronto e posto como definitivo" (p. 137). Vale ressaltar, que embora tais noções sejam aristotélicas (1964), ainda nos ajudam a entender a sociedade.

Assim, aqui, o "já-dito" e o "a-se-dizer" (ORLANDI, 2011, p. 09) perpassam discursos e práticas pedagógicas, pela tensão que existe na produção da linguagem, que ocorre na articulação do processo parafrástico e o polissêmico, ou seja, na "tensão entre o texto e o contexto histórico-social" (p. 27).

Tais relações objetivam nos encaminhar para os mecanismos políticos, sociais e ideológicos que permeiam a atuação do professor em suas práticas pedagógicas, o universo da escrita e as leituras que fazem dos textos dos alunos, pois, como nos aponta Orlandi (2012, p. 23), a noção de que o sujeito se apropria de forma individual da linguagem é falsa, uma vez que a tal apropriação não só é social como também interpelada pela ideologia.

Dito isso, é preciso explicitar suas relações com as práticas de ensino na escola e não nos limitarmos somente a rir, detestar os resultados, ou, ainda, fazer uso da notícia (superficial) para, de forma muitas das vezes até leviana, desqualificar estudantes e seus professores, como nos alerta Magda Soares. 
A mesma autora (1988), através de uma perspectiva social, analisa o ensino e o trabalho com a linguagem no contexto escolar. Nesse foco, apresenta questões históricas e sociais que nos ajudam compreender o que motiva as escolas a terem práticas de linguagem essencialmente voltadas para a normatização do uso da língua, o que consequentemente se estende, mais rigorosamente, para a produção textual.

Partindo da pergunta, "uma escola para o povo ou contra o povo?” (SOARES, 1988, p. 08, destaques da autora), Magda Soares inicia a apresentação de um panorama discursivo e de ideologias que visavam explicar/justificar o que muitos chamam de "fracasso" no domínio da língua "culta". Segundo ela:

So Brasil, o discurso em favor da educação popular é antigo: precedeu mesmo a proclamação da República. Já em 1882, Rui Barbosa, baseado em exaustivos diagnósticos da realidade brasileira da época, denunciava a vergonhosa precariedade do ensino para o povo no Brasil e apresentava propostas de multiplicação de escolas e de melhoria qualitativa do ensino (SOARES, 1988, p. 08).

De acordo com Soares (1988, p. 08), mesmo em épocas de "regimes autoritários, antiliberais e antidemocráticos dos períodos 1937-1945 (Estado Novo) e 1964-1985" o discurso oficial de “educação como direito de todos", ou ainda, "igualdade de oportunidades educacionais" está presente e é na origem social que se pautam as ideologias que objetivam justificar o que chamam de fracasso escolar.

Dentre essas correntes, está a "ideologia do dom", que defende a ideia de que uma vez na escola os estudantes encontram-se nas mesmas condições, em "igualdade de oportunidades", e o “fracasso" ou "sucesso" depende da "aptidão, inteligência, talento" próprio (SOARES, 1988, p. 10). Já a ideologia da "deficiência cultural" coloca o estudante das classes populares como em condições de “desvantagens", de "inferioridade', ao contexto de "superioridade" cultural dos alunos provenientes da classe dominante. Para os defensores dessa ideologia, o "fracasso" da escola pública é proveniente de “deficiência cultural" ou "privação cultural", fazendo uma relação ideológica e preconceituosa de que o meio em que vivem os alunos das classes populares é pobre tanto economicamente quanto culturalmente, resultando no "fracasso escolar". As duas ideologias apresentadas são apontadas por Soares como responsáveis por atribuir ao aluno e não às práticas escolares o "fracasso". Nessa linha de pensamento, há ainda a ideologia das "diferenças culturais" que mais uma vez recorre à ideia de cultura para atribuir juízo de valor, onde o diferente culturalmente seria aquele a quem "faltam" os padrões culturais das classes dominantes. Assim, um aluno da classe popular "fracassa" pela sua "diferença cultural" que assume novamente a conotação da "deficiência".

Surge ainda a teoria do "déficit linguístico", que conforme seus defensores: 
as crianças das camadas populares chegam à escola com uma linguagem deficiente, que as impede de obter sucesso nas atividades e aprendizagem: seu vocabulário é pobre - não sabem o nome dos objetos comuns, usam frases incompletas, curtas, monossilábicas; sua sintaxe é confusa e inadequada à expressão do pensamento lógico; cometem 'erros' de concordância, de regência, de pronúncia; comunicam-se muito mais através de recursos não-verbais que de recursos verbais. Em síntese: são crianças ‘deficitárias’ linguisticamente (SOARES, 1988, p. 20).

Ainda segundo Soares (1988), como explicação para tal quadro, recorre-se à ideia de que a criança da classe popular vive em um ambiente "pobre" de estimulações verbais, uma vez que a criança da classe favorecida:

vive num ambiente rico em estimulações verbais: é incentivada a perguntar e a responder, é ouvida com atenção, os adultos leem para ela e as situações de interação verbal são numerosas e estimuladoras da reflexão, da abstração, do pensamento lógico. Como consequência, a criança desenvolve-se linguística e cognitivamente, e não enfrenta dificuldades de aprendizagem quando ingressa na escola (p. 21).

Dessa forma, o "déficit linguístico" é visto como resultado da "privação linguística" que a criança vive em sua família e contexto cultual (SOARES, 1988).

A apresentação das ideologias acima tem como objetivo não só situar teoricamente o avanço das discussões contemporâneas sobre o trabalho com a linguagem na escola, mas também chamar a atenção para concepções preconceituosas e de perpetuação da visão do aluno da escola pública como aquele que "fracassa" no domínio dos códigos de linguagem verbal por deficiências que são causadas por sua classe social. Infelizmente não são poucos os professores (e cidadãos) que reproduzem a ideologia de que temos uma língua "culta", um discurso "culto", uma "alta" cultura e que aqueles que não as possuem são "necessitados", “carentes", “desprivilegiados" e/ou "deficientes".

Nessa perspectiva, temos milhares de escolas para as classes populares que entram em um tipo de maratona cultural. Nela, adquirir a cultura, a língua, as linguagens impostas pelas classes dominantes é o caminho para deixar de ser "deficiente". Ou seja, nesse sentido, ser "diferente" é ser "deficiente".

Nesse ponto, não podemos deixar de problematizar uma aparente solução adotada por muitos dos que trabalham com o ensino da língua e da escrita. Trata-se do "bidialetalismo funcional".

A palavra aparente precede o vocábulo solução porque suas contradições e limites nem sempre são percebidos ou debatidos, exercendo muitas das vezes a função de "camuflador", como veremos a seguir. 
O "bidialetalismo funcional" traz para o centro escolar questões sobre o ensino da língua e as variações linguísticas. No "bidialetalismo", postura mais adotada pedagógica e socialmente, segundo Soares, os "falantes de dialetos não-padrão devem aprender o dialeto-padrão, para usá-lo nas situações em que ele é requerido: isto é, a solução educacional seria um bidialetalismo funcional" (SOARES, 1988, p. 49). Porém, por não se tratar de um processo consciente e que está ligado à identidade do falante, não é de fácil imposição. Quando se refere à postura mais adotada, a autora está contrapondo-a à postura mais radical em que:

o ideal, segundo essa perspectiva, seria uma sociedade livre de preconceitos linguísticos, em que cada um pudesse usar seu próprio dialeto, sem medo do ridículo ou da censura, e uma escola que não interferisse no comportamento linguístico dos alunos, interferência que constitui, segundo os partidários dessa postura, um verdadeiro imperialismo educacional. Seria, nesse caso, desejável que o ensino, os livros escolares, a alfabetização utilizassem o dialeto dos alunos, em vez do dialetopadrão (p. 49).

Uma vez apresentadas as vertentes do "bidialetalismo", é preciso problematizá-las. A corrente mais radical pode ser refutada mais rapidamente por reconhecermos que seria necessária uma mudança de ideologia e de postura de toda sociedade para que o estudante não continuasse a sofrer as consequências de usar unicamente seu dialeto. Vale ressaltar que estamos longe, embora muitos sociolinguistas estejam trabalhando para tal, de conseguirmos um respeito de uso e igualdade de variações linguísticas, uma vez que é também a língua o reflexo da dominação de uma classe social sobre a outra (econômica e culturalmente). Outra questão envolvida se dá pelo fato de que banir totalmente da escola o dialeto-padrão seria também uma forma de preconceito linguístico, de intolerância ao diferente.

Descartada a hipótese dos radicalismos, nos concentremos na que aparentemente é mais justa: a de que os estudantes usariam o seu dialeto ou o dialeto-padrão, conforme a ocasião. Assim, se eles estivessem em uma reunião familiar, falariam como os demais de sua comunidade cultural. Já na escola, ou em uma situação formal, que requer o uso da norma padrão, como uma entrevista de emprego, por exemplo, ele usaria o dialeto-padrão. Perfeito, diriam muitos. Mas a escola tem conseguido cumprir esse papel?

A resposta também nos remete às desigualdades sociais, pois, a escola pública não tem conseguido cumprir tal tarefa. Já as escolas que são voltadas para as classes dominantes conseguem com êxito esse resultado, pois o dialeto por estas utilizado já é o padrão e, nesse caso, não há esforço ou violência sobre os estudantes dessas classes tendo em vista que esse universo simbólico lhes é familiar, além das condições materiais de que essas dispõem para a realização do seu trabalho. 
Redirecionar a discussão para as desigualdades de classes, as condições de produção e as práticas de ensino é um passo necessário, em prol do entendimento de que a estrutura social é que impõe os limites não só do que o povo come, mas também do que deve aprender.

Pode parecer desanimador trabalhar com o ensino da produção textual, justamente porque as tensões que envolvem o ensino da língua já são tantas e são inevitavelmente potencializadas quando a escrita é o desafio.

Porém,

[...] desenvolvido trabalho sistemático dirigido à compreensão das formas pelas quais se produzem os sentidos, os alunos são capazes de assumir diferentes perspectivas diante de textos significativos, questionar o que é tido como dado, e argumentar redimensionando o objeto da interlocução. Em síntese, rompida a prática da repetição do já-dito e estabelecidas condições favoráveis, os alunos são capazes de articular discursos críticos (BARRETO, 1994, p. 39, destaques meus).

Assim, a partir da perspectiva da capacidade dos alunos de se reconhecerem enquanto sujeitos produtores de discurso, somada a uma formação voltada para a leitura polissêmica, esses têm a capacidade de romper com o "já-dito". Ou seja, assumirem a condição de sujeitos articuladores de discursos críticos, na linguagem oral e na escrita.

Entretanto, as condições de desenvolvimento desse processo também precisam ser problematizadas, o que será feito a seguir.

\section{A PRODUÇÃO TEXTUAL, A LEITURA E SUAS CONDIÇÕES NA ESCOLA PÚBLICA DE ENSINO MÉDIO}

Quando voltamos nosso olhar para as condições de produção (ORLANDI, 2011) das produções textuais na escola pública de ensino médio, temos, de um lado, professores que, na sua maioria, possuem uma carga de trabalho elevada, atuando em três instituições ou mais, com salários que só aumentam relevantemente se o profissional elevar sua carga horária de trabalho, com turmas de mais de 40 alunos e precárias condições de trabalho.

Essa síntese nos permite mapear a relação que esse professor geralmente possui com o ensino de produção de texto, entendida cada vez mais como um trabalho extra, cansativo e infindável, uma vez que corrigi-las demanda muito tempo, esse geralmente retirado da vida pessoal do professor.

Do outro lado, temos alunos, salvo exceções, produzindo seus textos: a) a partir de temas que pouco ou nada interessam a eles; b) sem nenhuma discussão prévia com o professor e/ou com a turma sobre o assunto; c) com um mínimo e máximo de linhas para escrever (entre 20 e 30 linhas - 
limites iguais aos das regras do Enem, Vestibulares e concursos e que desde o Ensino Fundamental estão presentes através do discurso pedagógico de que é para treinar o poder de síntese no dia dessas futuras avaliações externas, que na grande maioria das vezes está longínqua, principalmente para o caso do Ensino Fundamental I); c) têm-se em geral 50 minutos para o processo do rascunho à versão final; d) tal produção textual muitas vezes ocorre "entre uma aula de Geografia e duas de Química" (CASTRO, 2008, p. 142); e) “em uma classe de 30” ou 50 (atualmente) “outras pessoas” (idem). Tudo isso diante, ainda, da pressão de que o professor irá avaliar aquele texto e dará uma nota que somará a outras para que o estudante passe para a série seguinte, sem falar na tão sonhada aprovação no Enem ou vestibular, avaliações essas usadas como justificativas (objetivos) desse difícil processo, ao qual são submetidos milhares de estudantes.

Diante dessas condições de produção, não podemos deixar de trazer dois livros, são eles: Minhas férias, pula uma linha, parágrafo (GRIBEL, 2010) e Por que escrever?: uma discussão sobre o ensino da produção textual (CASTRO, 2008). Embora o primeiro seja um livro infantil e o segundo fruto de uma tese de doutorado, ambos problematizam de forma crítica as condições de produção nas quais a produção textual está inserida. Comecemos pelo texto de Gribel (2010, p. 8-9).

A professora puxou a cadeira dela e se sentou. Atrás dela, no quadro-negro, eu vi decretado o fim das nossas férias e o fim do nosso primeiro dia de aula sem aula. Estava escrito: Redação: escrever trinta linhas sobre as férias. Eu sabia que as férias de ninguém iam ser mais as mesmas na hora que virassem redação. É simples: férias é legal, redação é chato. Quando a gente transforma as nossas férias numa redação, elas não são mais as nossas férias, são a nossa redação. Perdem toda a graça. [...] Além do mais, eu tenho certeza de que a professora nem quer saber de verdade como foram as nossas férias. Ela quer só saber como é a nossa letra e se a gente tem jeito para escrever redação.

Embora seja literatura infantil, Gribel, ao longo de todo livro e de uma forma bem-humorada, nos remete não só às antigas aulas de redação. Nele, nos deparamos também com práticas e angústias dos estudantes que se perpetuam nas atuais aulas de produção textual, uma delas é a de que "redação continua sendo chato", mesmo após a "nova lexicalização" (FAIRCLOUGH, 2008). Outra é a de que o professor não abre espaço para uma efetiva interação com o sujeito/autor daquele texto, o que frustra o estudante por ser aquela escrita fruto de um grande esforço linguístico/discursivo diante das condições de produção nas quais o jovem está inserido.

Nas palavras de Castro (2008, p. 34):

O que predomina em nossas escolas está longe de constituir um ensino de produção de textos. Salvo exceções, contribui para representações falsas quanto ao ato de escrever e a seus processos e 
produtos. Quando não impede que os alunos estabeleçam uma relação significativa com a produção, ao menos favorece a interposição de várias barreiras para que isso ocorra dentro e fora da escola.

A análise de Castro, somada às questões já apresentadas, nos remete à difícil, provocante e necessária pergunta contida no título de seu livro: Por que escrever?

A indagação parece ganhar forma de eco, principalmente quando: a) estamos na escola pública, diante de todas as questões sociais e políticas nas quais está inserida; b) não trabalhamos com a ideia de que sejamos todos escritores um dia. Entretanto, a pergunta nos remete, ainda, a outra questão fundamental: ao pressuposto de que enquanto professores temos um papel na formação discursiva dos estudantes.

Nessa perspectiva, entendemos que a produção textual escolar, tal como tem sido ensinada e cobrada, está cada vez mais distante da polissemia, contribuindo sistematicamente não só para a paráfrase discursiva, mas já, a passos cada vez mais largos, constituindo, salvo exceções, a prática da cópia propriamente dita, repetições acríticas, de quem é ensinado essencialmente a preencher lacunas, a folha em branco.

Para uma diferente realidade seria necessária uma efetiva discussão e mudança dos currículos, das práticas pedagógicas, de ideologias. Porém, os alunos da escola pública contemporânea estão inseridos em uma escola dual, conforme conceituação de Gramsci (1995), que assume o discurso da democracia educacional, mas pauta-se na paráfrase discursiva, ideológica, sendo tal reforma na estrutura educacional um projeto longe de se tornar realidade sem uma mudança ideológica e hegemônica na sociedade.

O conceito de Gramsci sobre a dualidade na educação parte da coexistência de um projeto educacional distinto para classes distintas. Nas palavras do autor:

[...] ao lado do tipo de escola que poderíamos chamar de "humanista" (e que é o tradicional mais antigo), destinado a desenvolver em cada indivíduo humano a cultura geral ainda indiferenciada, o poder fundamental de pensar e de saber se orientar na vida, foi-se criando paulatinamente todo um sistema de escolas particulares de diferente nível, para inteiros ramos profissionais ou para profissões já especializadas e indicadas mediante uma precisa individualização. [...] A divisão fundamental da escola em clássica e profissional era um esquema racional: a escola profissional destinava-se às classes instrumentais, ao passo que a clássica destinava-se às classes dominantes e aos intelectuais [...]. A tendência, hoje, é a de abolir qualquer tipo de escola "desinteressada" (não imediatamente interessada) e "formativa", ou conservar delas tão somente um reduzido exemplar destinado a uma pequena elite de senhores e de mulheres que não devem pensar em se preparar para um futuro profissional, bem como a de difundir cada vez mais as escolas profissionais especializadas, nas quais o destino do aluno e sua futura atividade são predeterminados [...] (GRAMSCI, 1995, p. 117-118). 
Dentro da perspectiva da escola dual, no sistema de ensino voltado para as classes subalternas, uma formação discursiva voltada para a produção de sentidos contra-hegemônicos é posta de lado, em função não só de uma perspectiva instrumental, mas também ideológica, sendo, assim, negadas as condições tanto estruturais (como a circulação de múltiplos textos) até didáticas, como práticas que fujam aos modelos e temáticas propostas pelas diretrizes e discursos pedagógicos institucionais.

Diante desse contexto, é preciso buscarmos estratégias que possibilitem o ensino da produção textual pautado em um projeto de formação discursiva em que o sujeito, a partir das suas condições de vida, possa reconhecer as ideologias e os discursos hegemônicos, as diferenças sociais e as incoerências entre discursos circulantes e a realidade vivida. Dessa forma, tomo como base o conceito da ideologia como hegemonia de sentidos, articulando também Gramsci a Fairclough (2008, p. 116), pela perspectiva de "investigar as práticas discursivas como formas materiais de ideologia".

Nesse sentido, é possível vislumbrar a problematização das condições de produção de texto, que reconhecida e declaradamente angustiam (limitam?) os alunos, como um ponto para reflexões críticas de tal contexto e também a possibilidade de uma formação discursiva contra-hegemônica. Tal ideia parte do entendimento de que estando os alunos da escola pública, escola interessada, conforme Gramsci, em condições de produção desiguais aos da escola desinteressada, um trabalho de produção de sentidos contra-hegemônicos seja tanto uma real possibilidade quanto necessária prática.

Acreditamos, ainda, que tal projeto seja um possível caminho ao propormos um olhar e uma prática discursiva que problematize com os estudantes das classes populares a percepção das ideologias dominantes e a necessidade de se produzir discursos que condizem com as reais condições em que estão inseridos, já que os estudantes das classes dominantes são formados para reproduzirem os discursos ideológicos de sua realidade social, sendo um trabalho de discurso contra-hegemônico com eles mais difícil, para não dizer reprimido pelas escolas interessadas, uma vez que ela exerce o papel de reprodução de suas ideologias, com as finalidades do sistema capitalista (ORLANDI, 2011, p. 207), o que nos faz relembrar também que "não há uma relação automática, mecânica, entre 'ter o domínio cultural', e 'ser crítico”’ (p. 210).

Vale ressaltar, ainda, que é necessário pensarmos um ensino como mecanismo não de reprodução de sentidos, mas de uma formação crítica voltada para o trabalho com sentidos contrahegemônicos, sem esquecer que a consciência crítica não resolve ou transforma a realidade social por si. Uma vez que:

[...] além de soluções restritas ao percurso pedagógico, se deverá, necessariamente, encarar o fato de que, em relação às diferenças de classe, a educação é apenas um elemento entre muitos outros de 
uma política efetiva de justiça social e nem é o mais importante ou mais decisivo deles. (ORLANDI, 2011, p. 207).

Assim, retornamos à pergunta de Castro: Por que escrever? E acrescentamos: Por que ensinar a escrever na escola destinada às classes populares?

Poderíamos nos ater como resposta ao fato de que ao escrever o sujeito depara-se com o desafio de elaborar seus pensamentos através da apropriação dos códigos linguísticos e sociais que legitimam organicamente as relações de poder, possibilitando a ele uma intervenção não só prática, como também crítica do contexto no qual está inserido. Assim, a noção de crítica se dá pelo viés da percepção do todo, ou seja, a relação que o sujeito faz com a questão macro e micro que envolve o social, sua língua, linguagens e discursos.

Entretanto, quando a escola consegue promover uma prática de leitura, é somente pela via da imposição (cobrando resumos dos livros) ou do estímulo? Há diálogos com os alunos sobre as suas histórias de leituras e preferências ou dá-se como única opção os cânones, que por sinal são os mesmos que compõem as provas das escolas e as de avaliação externa? Esses questionamentos são respondidos na análise de Barreto (1994) sobre a leitura no cenário escolar:

Do ponto de vista da cena discursiva posta na escola (Barreto, 1993c), nos limites do autoritarismo do discurso pedagógico [...], a leitura tende a ser feita em condições que inviabilizam o diálogo: "textos didáticos" como pretexto para a abordagem gramatical, perguntas literais a serem respondidas por escrito, respostas que podem ser simples transcrições de frases contidas no texto, etc. Leitura parafrástica, retorno constante ao dizer sedimentado, simples repetidora dos sentidos legitimados. (p. 31).

Trago mais uma indagação de Eni Orlandi: "Leitura: questão linguística, pedagógica ou social?" A resposta da autora vem logo a seguir, quando reconhece a importante função do trabalho intelectual da escola nesse quesito, mas critica a discussão pautada no caráter técnico e instrumental da questão, que resulta no que chama de redução ao "pedagogismo". Vejamos:

O pedagogismo, para mim, é acreditar em soluções pedagógicas desvinculando-as do seu caráter sócio-histórico mais amplo: para resolver a questão da leitura se propõem técnicas para que se dê conta, em algumas horas semanais, dessa propalada incapacidade (ORLANDI, 2012, p. 46).

Partindo do pressuposto de que a educação é uma educação de classe e de que a "Educação" "é da classe dominante do sistema capitalista, com suas finalidades" (ORLANDI, 2011), que pautase no discurso do poder e da exclusão, uma vez que o seu saber é que precisa ser adquirido e de que fora desse conhecimento só há um saber menor. Nesse sentido, ou se é igual ou se é menos. Assim, instala-se também na educação a divisão social que legitima o conhecimento da classe dominante e desconsidera os demais conhecimentos. 
Ao considerarmos ignorância e não resistência cultural quando alguém do povo apresenta uma relação diferente do previsto com um bem cultural, assim como ocorre também com a língua materna e a leitura, estamos diante do retrato de uma educação/“escola democrática domesticada pelo dominante" (ORLANDI, 2011, p. 212).

Dito isso e apresentados aspectos do quadro social, histórico, econômico e de classes da leitura, que na grande maioria das vezes são atribuídos somente à questão cognitiva do aluno, já que muito se discute sobre a falta de domínio das fases da leitura, tal como "decodificação", "interpretação", "relação" (ROJO, 2009), e sua quase automática atribuição à "falta de competência" técnica por parte do professor, podemos, então, pensar o aluno-leitor da escola pública contemporânea não como um incapaz de dar conta de uma habilidade, tida por muitos da sociedade como sendo tão "fácil e prazerosa", mas entendê-lo como sujeito de uma trama social em que lhe são negadas suas leituras de mundo, impondo-lhe as formas de leitura e sentidos hegemônicos.

É com Petit (2010, p. 103) que podemos entender a rejeição que muitos estudantes das classes populares têm com relação à leitura, já que a autora entende esse movimento como uma forma de "resistência" à dominação sofrida, que está direta ou indiretamente ligada ao que define como "medo do livro, ou ao menos de alguns dos seus aspectos". Para que essas noções sejam compreendidas, é preciso observar, ainda, a relação estabelecida entre a leitura e "controle".

Uma delas é a de que "o domínio da língua e o acesso aos textos impressos foram por muito tempo privilégio daqueles que detinham o poder, ou seja, os notáveis, os representantes do Estado e da Igreja" (PETIT, 2010, p. 103-104). Vale ressaltar que quando o acesso a esses textos iniciou novas formas de controle foram exercidas. Ou seja, Estado e Igreja tentam fiscalizar os leitores.

Nesse sentido, “obcecada pelos perigos da leitura no meio popular, a igreja católica, em particular, condenou durante muito tempo as leituras não controladas da Bíblia ou das obras profanas e se esforçou em fazer da leitura um gesto coletivo e enquadrado" (PETIT, 2010, p. 107).

Historicamente, os detentores "do poder - político, religioso, simbólico ou doméstico -" (PETIT, 2010, p. 111) tentam monopolizar os sentidos. Para exemplificar tal necessidade/prática, vejamos mais uma vez exemplos dados por Petit. O primeiro, a autora define como uma "[...] fórmula de misoginia [...]" (PETIT, 2010, p. 111), defendida por Restif de La Bretonne, escritor francês do século XVIII, segundo ele:

Seria preciso proibir que todas as mulheres tivessem acesso à escrita e à leitura. É um modo de restringir suas ideias e limitá-las aos cuidados úteis da casa; uma maneira de lhes incutir respeito pelo primeiro sexo; os homens receberiam uma educação primorosa, enquanto as mulheres, não. (PETIT, 2010, p. 111-112). 
Outro exemplo pauta-se em leis que vigoraram até o século XIX, "particularmente na Carolina do Sul” (PETIT, 2010, p.112). Nelas, havia a proibição de que os negros aprendessem a ler, pois, "os proprietários de escravos temiam que os negros encontrassem nos livros ideias revolucionárias que pudessem ameaçar seu poder" (PETIT, 2010), ou, ainda, "através da leitura de panfletos pedindo a abolição da escravatura ou mesmo pela Bíblia, eles poderiam se abrir às ideias de revolta, de liberdade. [...]". Assim, alguns proprietários chegavam a enforcar qualquer escravo que tentasse ensinar os outros a ler" (PETIT, 2010). Aqui, o medo do livro acompanha os donos do poder, mas ele também está presente entre as classes populares, associado à resistência, como veremos a seguir.

Hoje, o controle dos sentidos passa por outras estratégias e uma delas é a escola. Entretanto, para que entendamos alguns dos motivos que afastam os estudantes dos livros precisamos perceber duas questões que contribuem para tal.

O primeiro destaque é pautado na antítese dos exemplos citados anteriormente, a falta de acesso. Contraditoriamente, temos na contemporaneidade discursos políticos, sociais e familiares de que é preciso ler, é preciso ler, é preciso ler... Nessa lógica, tem-se construído uma relação utilitarista com a leitura, já que "a leitura é vista agora pela maioria dos pais como um capital, e tanto as pessoas do campo como as da cidade lamentam em uníssono que 'os jovens não leem o suficiente"” (PETIT, 2010, p. 122).

Porém, esse desejo de que se leia tem sido pautado em uma visão "utilitarista, restrita" (PETIT, 2010), uma vez que é preciso ler para aprender/melhorar os conhecimentos sobre a língua, assim como para ter acesso ao conhecimento dos poderosos, para tirar notas altas na escola etc.

Nessa lógica, estamos todos, contraditoriamente ao que viveram nossos antepassados, diante da obrigação de ler.

Esse discurso social incorporado pela escola, muitas vezes, busca fornecer "aos jovens meios de libertá-los dos determinismos sociais" (PETIT, 2010, p. 123). Porém, "se alguns professores fazem de tudo para 'empurrar' as crianças para ajudá-las a evitar o que é preestabelecido, outros, infelizmente, contribuem para que a escola funcione como uma máquina de reprodução social, uma máquina de exclusão" (PETIT, 2010). Ou seja, se trabalharmos a leitura na escola a serviço da gramática, da avaliação e não do diálogo, pautada no que Orlandi (2012) chamou de pedagogismo, corremos o risco de reduzirmos a leitura a uma mera função instrumental (PETIT, 2010).

Nessa lógica, acabamos colaborando de forma direta para limitar o acesso dos estudantes à polissemia da linguagem e assim controlando-os, excluindo-os, com práticas pedagógicas em que eles não se reconhecem, tanto gramatical quanto literariamente, já que, para muitos, a "língua dos 
livros é a língua do poder. Daí as condutas defensivas para compensar sua marginalização cultural, sua exclusão simbólica, política" (PETIT, 2010, p. 124). É preciso compreender também que perpassam a esses contextos diversos outros medos, como o de se distanciar da identidade do grupo ao qual se pertence.

Nesse sentido, o "fracasso" escolar e o distanciamento do livro podem ser uma forma, inconsciente, não só de rejeitar a cultura letrada, como também do medo do deslocamento para o desconhecido. Essa ideia pauta-se na visão de que, "frequentemente, nos meios populares, o 'intelectual' é considerado suspeito; é colocado de um lado como um pária, considerado um 'puxasaco', maricas, traidor de sua classe, de suas origens etc.” (PETIT, 2010, p. 126).

\section{COMO LEMOS OS TEXTOS DOS ESTUDANTES?}

Precisamos debater, também, a leitura, a produção textual e os aspectos linguísticos dos estudantes pelo viés do olhar do professor, ou seja, as leituras feitas pelo docente. Assim, a discussão a seguir será em torno das condições de leitura do professor sobre a produção textual escolar de seu aluno.

Como ponto de partida, tomemos a seguinte análise de Barreto:

$\mathrm{Na}$ administração do cotidiano escolar, ficam evidentes: o respeito a uma hierarquia "naturalizada", a valorização da obediência, e a imposição do silêncio ao aluno que, mesmo adulto, tende a ser infantilizado.

Na sala de aula, um professor marcado pela ambiguidade: dotado de poder via saber (mesmo que, pelo esvaziamento da sua formação, este saber se limite à paráfrase do discurso alheio), com o salário aviltado, mas com valores que o levam a se identificar com a classe alta e não com as pobres.

Daí o risco crescente do abuso de poder como forma de exorcizar seu medo, seja na concretude da avaliação, seja no dia a dia, através de atitudes que podem variar da discriminação sutil à hostilidade assumida (BARRETO, 1994, p. 45-46).

O enredo é quase sempre esse:

O exercício de redação, na escola, tem sido um martírio não só para os alunos, mas também para os professores. [...] Para o professor [...] vem a decepção de ver textos mal redigidos, aos quais ele havia feito sugestões, corrigido, tratado com carinho. No final, o aluno nem relê o texto com as anotações. Muitas vezes o atira ao cesto de lixo assim que o recebe (GERALDI, 2012, p. 64-65).

Se no cotidiano escolar reconhece-se o exercício do autoritarismo como forma de se exorcizar os próprios medos e a repressão, reconhecida ou subjetiva, na leitura e correção dos textos escolares dos estudantes essa prática não fica de fora, nem mesmo nas de muitos professores que 
gostam de trabalhar com produção textual e a veem como um instrumento de polissemia discursiva. A afirmativa é contraditória. Vejamos seu fundamento.

Somado a todo o contexto de tensões e decepções que envolvem a profissão e suas condições de produção, a frustração de não ter a "recompensa" de seu trabalho via notas altas de seus alunos acaba por agravar o quadro.

Estamos diante do que Geraldi (2012) caracteriza como sendo função-aluno e funçãoprofessor. Nesse enredo, o primeiro escreve um texto obrigado, para ser lido somente por aquele profissional, que, em geral, buscará apontar todos os “erros" e raramente debaterá de forma individual os caminhos possíveis para uma melhora.

Já o segundo, não consegue se ver enquanto instrumento de coerção de estudantes que, na prática da escrita, são obrigados a escreverem sobre o que a escola quer, nas condições de espaço e tempo que ela impõe. Ou seja, a leitura do professor sobre os textos de seus alunos é a leitura imposta pelo sistema educacional e social, ao qual se está submetido.

Assim, o jogo da paráfrase pauta-se em regras que levam o professor também na condição de leitor de seus alunos a ser guiado pela normatividade, em uma situação artificial do emprego da língua (GERALDI, 2012, p. 65), sem dimensioná-la social, subjetiva e criativamente. Dito de outra forma, a "leitura é produzida" (ORLANDI, 2011, p. 193), mesmo a do professor.

No que tange ao professor e sua formação, pouco se discute a função social do mesmo da escola pública, pautando seu currículo acadêmico, aulas e discursos, essencialmente, em uma visão técnica e pedagógica.

Para esse profissional são ensinados conceitos tradicionais relacionados à ideia de que o cânone e a gramática representam a herança cultural, literária e uma tradição a ser repassada, embora, reconhecemos, existam mestres na contramão dessa formação.

Quando no lugar da exceção, temos, sim, também na escola básica, professores que valorizam a cultura e a expressão popular, às vezes em conflito por estar fazendo a "coisa errada". Há, ainda, os que têm claro em suas práticas educacionais diálogos equilibrados, respeitosos e interessantes entre o erudito e o popular. Porém, vale ressaltar que esses, geralmente, enfrentam não só críticas, como coerções em suas práticas por estarem "fugindo" do currículo.

Vale ressaltar que:

É preciso encarar a prática pedagógica na trama social, sem ingenuidade ou pretensão, com atenção ao "enredo" da/na linguagem mesma, sem onipotência ou impotência enquanto construções 
monolíticas da "pré-potência", buscando, na dialética das relações, as possibilidades implicadas nos limites (BARRETO, 1994, p. 39. (Destaque da autora).

Nesse sentido, temos as ideias de Bakhtin, quando problematiza os gêneros do discurso. $\mathrm{O}$ foco dado para as nossas reflexões e recortes temáticos está pautado na "teoria da enunciação", já que o conceito de "enunciado" usado pelo autor é definido como "ato de anunciar, de exprimir, transmitir pensamentos, sentimentos, etc. em palavras" (BAKHTIN, 2011, p. 261) e sua relação direta com a "construção composicional" (p. 261), com base, ainda, no pressuposto de que "a filosofia marxista de linguagem deve justamente colocar como base de sua doutrina a enunciação como realidade da linguagem e como estrutura sócio-ideológica” (BAKHTIN, 1992, p. 126).

Diante desse pressuposto, é a noção bakhtiniana de língua tomada como referencial:

\begin{abstract}
A língua existe não por si mesma, mas somente em conjunção com a estrutura individual de uma enunciação concreta. É apenas através da enunciação que a língua toma contato com a comunicação, imbui-se do seu poder vital e torna-se uma realidade. As condições de comunicação verbal, suas formas e métodos de diferenciação são determinados pelas condições sociais e econômicas da época. As condições mutáveis da comunicação sócio-verbal precisamente são determinantes para as mudanças de formas que observamos no que concerne à transmissão do discurso de outrem. Além disso, aventuramo-nos mesmo a dizer que, nas formas pelas quais a língua registra as impressões do discurso de outrem e da personalidade do locutor, os tipos de comunicação sócio-ideológica em transformação no curso da história manifestam-se com um relevo especial (BAKHTIN, 1992, p. 154).
\end{abstract}

Ao entendermos a língua não como algo existente por si mesma, mas situada a partir de seu contexto histórico, social, econômico e ideológico assumimos um posicionamento de trabalho de ensino da mesma, na escola, pautado em um deslocamento do foco do aprendizado nas regras gramaticais, que usa a escrita, na grande maioria das vezes literária, como ponto de partida e de chegada.

Caso contrário, corre-se o risco de uma redução na condição do aluno significador em suas práticas de linguagem, uma vez que o estudante, nessa condição, seria reduzido a um "mero operador de instrumentos, cuja correta manipulação lhe permitiria acessar sentidos predeterminados" (CASTRO, 2008, p. 47).

Vale lembrar, ainda, que "a gramática tradicional despreza totalmente os fenômenos da língua oral, e quer impor a ferro e fogo a língua literária como a única forma legítima de falar e escrever, como a única manifestação linguística que merece ser estudada" (BAGNO, 2009, p. 74).

Não estamos, com isso, apontando para um ensino em que não se apresente as regras gramaticais e discursivas nas quais estamos inseridos. Essa postura resultaria em negar ao estudante 
as ferramentas e estratégias discursivas de domínio de seu idioma e apropriação dos mecanismos das linguagens. Contudo, o trabalho escolar com a língua/linguagens pode ganhar um olhar que vá além do gramatical, da "norma culta", se reconhecermos que:

Historicamente, a relação entre linguagem e língua se marca por restrições sucessivas, determinadas em última instância por fatores político-econômicos. A partir da linguagem verbal, que expressa a dimensão simbólica constitutiva da espécie humana e move os sujeitos à inter-ação, a língua é produzida como trabalho de/para "um código comum", num processo de formalização que a institui como "o código correto" e, até, como “norma culta” (BARRETO, 1994, p. 26).

Em se tratando de escola pública, uma educação de massa e institucionalizada, temos um Estado que tem como parâmetro de saber cultural e de linguagem as classes médias (BARRETO, 1994), o que resulta, na grande maioria das vezes, em um ostensivo trabalho sobre o mesmo: o cânone literário, as regras gramaticais, as linguagens e culturas que são valorizadas pelas classes médias, já que estas, segundo Orlandi (2011), são aquelas que exercem o papel de incorporar o conhecimento tido como legítimo, do poder dominante. Para Orlandi, "quando se adere ao conhecimento legítimo, se desconhece a luta de classes, a luta pela validade de outras formas (2011, p. 208). Assim, raramente abre-se espaço para o debate, o trabalho e muito menos a aceitação das múltiplas formas de expressão cultural e linguísticas pertencentes às classes populares.

Por entendermos “[...] que cada palavra se apresenta como uma arena em miniatura onde se entrecruzam e lutam os valores sociais de orientação contraditória" (BAKHTIN, 1992, p. 66) e que “[...] revela-se, no momento de sua expressão, como o produto da interação viva das forças sociais" (idem) é que percebemos o trabalho com a linguagem como uma ação política, sendo a escola um espaço em que essa ideia precisa ser diariamente problematizada e praticada por seus professores.

Nesse sentido, é importante pensarmos em práticas de ensino que contenham uma escrita que faça sentido enquanto expressão do aluno/autor, dado que é na direção do trabalho com o diálogo entre o erudito e o popular, o literário e o não literário, o dito e não dito, o hegemônico e o contra-hegemônico que se pode construir uma escola que caminhe para o "discurso polêmico", “polissêmico" (ORLANDI, 2011), para uma efetiva apropriação social da linguagem.

\section{REFERÊNCIAS}

ARISTÓTELES. Obras. Madrid: Aguilar, 1964.

Arte retórica e arte poética. Rio de Janeiro: Edições de Ouro, 1969.

BAGNO, Marcos. Preconceito linguístico. O que é, como se faz. São Paulo: Edições Loyola, 2009.

. A norma oculta: língua \& poder na sociedade brasileira. São Paulo: Parábola Editorial, 2012.

BAKHTIN, Mikhail. Marxismo e Filosofia da Linguagem. 6 $^{\text {a }}$ ed. São Paulo: HUCITEC, 1992. 
Estética da Criação Verbal. Introdução e tradução do russo Paulo Bezerra; prefácio à edição francesa Tzvetan Todorov. $4^{\mathrm{a}}$ ed. São Paulo: Martins Fontes, 2003. (Coleção biblioteca universal).

BARRETO, Raquel Goulart. Da leitura crítica do ensino para o ensino crítico da leitura. (Tese de Doutorado). Rio de Janeiro: Faculdade de Educação da Universidade Federal do Rio de Janeiro, 1994.

Discursos, tecnologias, educação. Rio de janeiro: EdUERJ, 2009. (Série Pesquisa em Educação. Práticas de linguagem).

CASTRO, Marcelo Macedo Corrêa e. Por que escrever?: (uma discussão sobre o ensino da produção textual). $2^{\mathrm{a}}$ ed. Rio de Janeiro: M. Corrêa e Castro, 2008.

FAIRCLOUGH, Norman. Discurso e mudança social. Izabel Magalhães, coordenadora da tradução, revisão técnica e prefácio. Brasília: Editora da Universidade de Brasília, 2001, 2008 (reimpressão).

GERALDI, João Wanderley. Portos de Passagem. 4. ed. São Paulo: Martins Fontes, 1997.

GRAMSCI, Antonio. Os intelectuais e a organização da cultura. Trad.: Carlos Nelson Coutinho. $9^{a}$ ed. Rio de Janeiro: Civilização Brasileira, 1995.

GRIBEL Christiane. Minhas férias, pula uma linha, parágrafo. Rio de Janeiro: Salamandra, 2010.

ORLANDI, Eni. A linguagem e seu funcionamento: as formas do discurso. 6. ed. Campinas, São Paulo: Pontes Editores, 2011.

Discurso e Texto: formulação e circulação dos sentidos. 3. ed. Campinas, São Paulo: Pontes Editores, 2008.

Discurso em análise: Sujeito, Sentido e Ideologia. 2. ed. Campinas, São Paulo: Pontes Editores, 2012.

Discurso e leitura. São Paulo: Cortez, 2012.

PETIT, Michèle. A Arte de ler ou como resistir à adversidade. São Paulo: Ed. 34, 2012.

Os jovens e a leitura. São Paulo: Ed. 34, 2010.

SOARES, Magda. Linguagem e escola: uma perspectiva social. 6. ed. São Paulo: Editora Ática, 1988.

Discurso ao receber o prêmio Almirante Álvaro. 2015. Disponível em: http://www.mcti.gov.br/visualizar//asset_publisher/jIPU0I5RgRmq/content/leia-o-discurso-de-magda-soares-ao-receber-o-premio-almirante-alvaroalberto;jsessionid=8684DEE68420446E08535A832BB29A0D. Acesso em: 25 jul. 2015.

ROJO, Roxane. Letramentos múltiplo, escola e inclusão social. São Paulo: Parábola Editorial, 2009.

\section{RESUMO}

O presente artigo busca compreender a temática da escrita sob o viés social, ideológico, relações de poder e sentidos que permeiam a dimensão discursiva, sendo a escola mais uma dessas arenas, conforme Bakhtin. Para tal, a abordagem teórico-metodológica assumida está centrada na linguagem como fenômeno ideológico, tradução mais pura e sensível das relações sociais. Outra linha adotada é a da Análise do Discurso, proposta por Eni Orlandi e pautada na tensão paráfrase-polissemia. Nesse sentido, buscando fugir de análises e propostas deterministas e mecanicistas, esse estudo centra-se, também, na articulação de possibilidades de estratégias para um ensino como prática da expressão, da crítica e da subjetividade do estudante.

Palavras-chave: Discurso. Ensino. Produção textual.

\section{"Cultured" and hidden norms in the teaching of mother tongue, reading and textual production ABSTRACT}

This article intends to understand the writing subject under the social, ideological bias, power relationships and meanings, that permeate the discursive dimension, considering the school one more of these arenas, according to Bakhtin. To do so, the adopted theoretical and methodological approach is centered on language as an ideological phenomenon, purer, and sensitive translation of social relations. Another thinking line adopted here is the Discourse Analysis proposed by Eni Orlandi, and guided by the paraphrase-polysemy tension. In this sense, and trying to escape from deterministic and mechanistic analysis and proposals, this study also concentrates on the articulation of strategy possibilities, aimed at a teaching as a practice of expression, criticism, and student's subjectivity.

Keywords: Speech. Teaching. Text production. 